\begin{abstract}
Iranica
Abstracta Iranica Revue bibliographique pour le domaine irano-aryen

Volume 34-35-36 | 2017

Comptes rendus des publications de 2011-2013
\end{abstract}

\title{
Jeremiah Losty et Malini Roy. Mughal India, Art Culture and Empire.
}

Isabelle Imbert

\section{(2) OpenEdition \\ 1 Journals}

Édition électronique

URL : http://journals.openedition.org/abstractairanica/41261

DOI : 10.4000/abstractairanica.41261

ISSN : 1961-960X

\section{Éditeur :}

CNRS (UMR 7528 Mondes iraniens et indiens), Éditions de l'IFRI

\section{Référence électronique}

Isabelle Imbert, « Jeremiah Losty et Malini Roy. Mughal India, Art Culture and Empire. », Abstracta Iranica [En ligne], Volume 34-35-36 | 2017, document 1, mis en ligne le 15 juillet 2016, consulté le 29 septembre 2020. URL : http://journals.openedition.org/abstractairanica/41261 ; DOI : https://doi.org/ 10.4000/abstractairanica.41261

Ce document a été généré automatiquement le 29 septembre 2020.

Tous droits réservés 


\title{
Jeremiah Losty et Malini Roy. Mughal India, Art Culture and Empire.
}

\author{
Isabelle Imbert
}

\section{RÉFÉRENCE}

Jeremiah Losty et Malini Roy. Mughal India, Art Culture and Empire. Catalogue

d'exposition de la British Library, 9 nov. 2012 - 2 av. 2013, Londres, 2012, 255 p.

1 Trente ans après l'exposition organisée par Jeremiah Losty (The Art of the Book in India, Londres, 1982.), la British Library consacre une exposition aux productions de peinture durant le long règne la dynastie moghole. Le catalogue, richement illustré s'organise en quatre chapitres. Il s'ouvre sur une carte du sous-continent, une généalogie des souverains moghols et un glossaire. Le catalogue contient 167 entrées associées à une bibliographie exhaustive des publications.

2 Le premier chapitre est dédié au patronage d'Akbar (r. 1555-1605). Il présente une sélection des plus somptueux manuscrits commandés par l'empereur, le Dārāb-nāme datable des années 1580-85 (Or.4615), le Bābūr-nāme produit entre 1590 et 1593 (Or. 3714), plusieurs peintures issues de deux copies de l'Akbar-nāme illustrées vers 1595 (Johnson Album 8,4) et 1602-3 (Or.12988), ainsi que d'autres manuscrits et peintures isolées. Organisé de manière chronologique, le matériel présente les principales caractéristiques de l'atelier de l'empereur, et se termine par un aperçu de l'attrait des peintres moghols pour les modes de représentation occidentales.

3 Le second chapitre est consacré au XVII ${ }^{\mathrm{e}}$ s., en particulier le patronage de Jahāngīr (r. 1606-1627) et Šāh Jahān (r. 1627-1658). Plusieurs manuscrits et pages d'albums illustrent les goûts et les centres d'intérêt des empereurs. Sont ainsi passés en revue des portraits des souverains, des représentations de mystiques et soufis, de femmes et d'Européens. Une lumière nouvelle est apportée à l'album Dārā Šikoh qui manquait jusque là de renouveau historiographique. Le chapitre se termine sur un portrait équestre d'Awrangzeb (r. 1658-1707). 
4 Le troisième chapitre s'intéresse à la diffusion des techniques mogholes dans les provinces au XVIII ${ }^{\mathrm{s}}$ s, et plus particulièrement à l'art du portrait. Il permet d'apporter de nombreux éclaircissements sur une période mal connue de l'art moghol et présente plusieurs écoles " provinciales » aux riches traditions artistiques.

5 Enfin, le quatrième et dernier chapitre est entièrement consacré au XIX ${ }^{e}$ siècle. L'objectif est de montrer que le naturalisme dérivé de l'art européen et assimilé par les peintres moghols donne naissance à un syncrétisme artistique encouragé par les nombreux commanditaires européens installés en Inde.

6 Ce catalogue d'exposition offre au lecteur néophyte un excellent aperçu des arts du livre moghols et constitue un formidable outil d'analyse aux chercheurs.

\section{AUTEURS}

\section{ISABELLE IMBERT}

Université Paris-Sorbonne 